УДК 37

DOI $10.21661 / \mathrm{r}-464039$

\title{
Ван Лися
}

\section{ОБУЧЕНИЕ КИТАЙСКИХ СТУДЕНТОВ РУССКОМУ ЯЗЫКУ \\ С УЧЕТОМ НАЦИОНАЛЬНОЙ ЯЗЫКОВОЙ ЛИЧНОСТИ (НАЧАЛЬНЫЙ ЭТАП ОБУЧЕНИЯ)}

Аннотация: работа посвящена описанию спечифики обучения китайских студентов русскому языку с учётом национальной языковой личности. Целью исследования является изучение особенностей учебного процесса по русскому языку в аудитории китайских студентов начального этапа обучения в условиях России. Описание базируется на выявлении национально обусловленных особенностей китайской языковой личности, что позволяет смоделировать оптимальные способы обучения русскому языку китайского контингента уровней $A 1-A 2$.

Ключевые слова: русский язык, иностранный язык, китайская языковая личность, обучение китайских студентов, начальный этап обучения, уровни А1A2.

\section{Wang Lixia}

\section{TEACHING RUSSIAN LANGUAGE TO CHINESE STUDENTS, TAKING INTO ACCOUNT THE NATIONAL LANGUAGE PERSONALITY (INITIAL STAGE OF TRAINING)}

Abstract: the work is devoted to the description of the specifics of teaching Russian to Chinese students, taking into account the national language personality. The aim of the study is to study the peculiarities of the educational process on the Russian language in the audience of Chinese students of the initial stage of education in the conditions of Russia. The description is based on the identification of the nationally determined features of the Chinese language personality, which allows to model the 
optimal ways of teaching the Russian language to the Chinese contingent of the level A1-A2.

Keywords: Russian language, foreign language, Chinese language personality, teaching Russian to Chinese students, the initial stage of training, level A1-A2.

Данная работа посвящзена вопросам оптимизации учебного процесса по русскому языку (далее: РЯ) в современной китайской аудитории начального этапа обучения (уровень А1-А2).

Целью данной работы является создание такой модели учебного процесса по РЯ, которая бы позволила осуществлять обучение иностранных (китайских) студентов с наилучшим результатом за определённую единицу времени, т.е. оптимально. Чтобы достичь поставленной цели, необходимо решить ряд вопросов:

1. Определить базовую модель обучения РЯ иностранных/китайских студентов, отвечающую требованиям современной лингводидактики.

2. Учесть специфику учебного процесса по РЯ в иностранной аудитории начального этапа обучения.

3. Учесть специфику учебного процесса по РЯ в конкретной национальной/китайской аудитории.

4. Определить и описать особенности китайской ЯЛ, изучающей РЯ.

5. Смоделировать учебный процесс, в наибольшей мере способствующий усвоению РЯ китайскими учащимися по оптимальным параметрам.

Новизна данной работы состоит в выявлении специфических национальных черт современной языковой личности (ЯЛ) китайского студента, опора на которые позволяет оптимально организовать учебный процесс данного контингента.

Анализ современных лингводидактических работ, в том числе и работ по методике преподавания русского языка как иностранного (РКИ) $[1 ; 4 ; 12 ; 14]$ позволяет нам заключить, что оптимальная базовая модель обучения РЯ иностранных, в том числе и китайских, студентов на современном этапе отвечает следующим требованиям: 
1. Имеет коммуникативно-деятельностную основу $[1 ; 9 ; 10 ; 12 ; 14]$, которая реализуется преимущественно за счёт коммуникативного и когнитивного принцุипов $[9 ; 10 ; 12]$.

2. Национально и личностно ориентирована $[2-5 ; 9,10 ; 12]$.

3. Учитывает достижения современной лингводидактики и смежных с нею наук, а также передовой практический опыт преподавания РЯ в иностранной аудитории $[1 ; 7 ; 14]$.

Вопросам обучения иностранных студентов РЯ с реализацией коммуникативно-деятельностной модели за счёт базовых коммуникативного и когнитивного принципов посвящены прежде всего работы А.А. Леонтьева [9]. Применительно к начальному и среднему этапу обучения данная модель была разработана последователями школы Д.И. Изаренкова: Л.П. Мухаммад, М.И. Цыреновой, Вень Яо и др. [6;10; 13].

Главными достижениями этих работ было определение таких отличительных черт личности иностранного студента, которые в наибольшей степени влияют на усвоение РЯ данными учащимися. Поскольку избранная указанными исследователями модель предполагает прежде всего обучение общению на изучаемом иностранном языке (ИЯ), следовательно, в качестве системообразующих личностных черт в коммуникативном аспекте были определены экстраверсия/интроверсия [10-12]. Также в процессе исследования экстравертивной/интровертивной ЯЛ иностранца, изучающего РЯ, было выявлено такое этнокультурно обусловленное качество ЯЛ, как проактивность. По мнению Л.П. Мухаммад, проактивность - качество экстравертивной/интровертивной ЯЛ, приобретённое в процессе обучения, или естественной коммуникации, позволяющее личности применять и экстравертивные, и интровертивные стратегии в зависимости от ситуации, от коммуникативных потребностей в момент общения [10].

Необходимость же соблюдения когнитивного принципа обусловила учёт таких свойств личности, как левополушарность (студенты, у которых при обучении доминирует анализ над синтезом) и правополушарность (доминирует синтез) $[2 ; 3 ; 10-12]$. 
Специфика учебного процесса по РЯ в иностранной аудитории начального этапа обучения на данный момент отражена как в теоретических, так и в практических работах. В качестве теоретических работ можно отметить работы следующих авторов: Э.Г. Азимова, А.Н. Щукина, Л.П. Мухаммад, М.И. Цыреновой $[1 ; 10 ; 13]$.

В качестве практических работ можно назвать программные и учебные материалы, аудио- и видеозаписи занятий в аудитории, расшифровки этих занятий и т. д. Ниже, опираясь на работы разработчиков Государственных стандартов для начального этапа обучения иностранцев, а также работы М.И. Цыреновой и Вэнь Яо, представим краткую характеристику н/э обучения в свете избранной нами базовой модели.

По мнению разработчиков Государственных стандартов для начального этапа обучения иностранцев при овладении ими базовым уровнем общения на РЯ (русском языке) студент должен уметь ориентироваться и реализовывать элементарные коммуникативные намерения в следующих ситуациях общения: «в административной службе (в деканате, в дирекции, в офисе, в паспортном столе); в магазине, киоске, кассе, на рынке; на почте, переговорном пункте; в банке, в пункте обмена валюты; в ресторане, буфете, кафе, столовой; в гостинице; в библиотеке; на занятиях, в университете; на улице, в транспорте; на экскурсии; в поликлинике, у врача, в аптеке; в ситуации общения по телефону» [7].

По мнению М.И. Цыреновой, жанры и тематика, актуальные для базового уровня, следующие: 1) монологи: а) о себе; б) мой друг; 3) моя семья... 2) объявление; плакат; каталог; поздравление; открытка; анкета [13].

Относительно языкового материала, покрывающего перечисленный выше коммуникативный минимум допустимо сказать, что это: 1) диалогические единства, обеспечивающие коммуникацию в заданных ситуациях; 2) четыре типа микротекстов, на которых строится монологическая речь (описание, повествование, рассуждение, инструкция); 3) лексико-грамматические единицы, покрывающие коммуникативный минимум, иными словами, базовая грамматика и лексика. Особенно это касается усвоения иностранцами связанных с универсальной 
семантикой: а) текстотеки; б) именных и глагольных форм, обеспечивающих коммуникацию «уровня выживания» [5; 6; 7; 10; 13$]$.

Специфика учебного процесса по РЯ в китайской аудитории описана такими исследователями, как И.А. Бобрышева, Л.П. Мухаммад, Ван Лися и др. [2; $5 ; 6 ; 11 ; 12]$.

В своих исследованиях И.Е. Бобрышева [2] отмечает, что главными особенностями китайской системы образования являются следующие: 1) ценность книги и преимущество письменных форм речи в учебном процессе; 2) опора на текст как источник информации, а также произведение, в котором систематизировано и синтезировано передаваемое содержание; 3) стратегия заучивания текста/текстов и опора на натренированную память; 4) тренировка памяти с помощью разработанной системы дриллов.

Мы согласны с выделенными И.Е. Бобрышевой особенностями китайской системы образования, однако в условиях российской образовательной среды данные особенности приобретают свою специфику. И эта специфика самым непосредственным образом связана с китайской ЯЛ, формировавшейся не только в стенах учебных учреждений, но прежде всего в интерактивном опыте заданной Конфуцием китайской этнокультуры. В связи со сказанным наиболее продуктивный подход - это подход «от личности», ЯЛ китайского студента, оказавшегося в иной этнокультурно обусловленной образовательной среде.

Наиболее корректно особенности современной китайской ЯЛ, изучающей РЯ, можно определить и описать, изначально опираясь на понятие «языковая личность», представленное в лингводидактике и смежных с ней науках.

Термин языковая личность (ЯЛ) обоснован в работе Ю.Н. Караулова «Русский язык и языковая личность» [8]. В своем исследовании китайской ЯЛ мы опирались на общеизвестное понятие ЯЛ, выработанное именно этим учёным: 1) любой носитель того или иного языка, охарактеризованный на основе анализа произведенных им текстов с точки зрения использования в этих текстах системных средств данного языка для отражения видения им окружающей действительности (картины мира) и для достижения определенных целей в этом мире; 
2) наименование комплексного способа описания языковой способности индивида, соединяющего системное представление языка с функциональным анализом текстов [8].

Поскольку в настоящее время отсутствует относительно полное и подробное описание ЯЛ китайского студента-филолога, мы считаем, что оптимальное моделирование учебного процесса в китайской аудитории затруднительно. В связи со сказанным все работы, посвящённые китайской ЯЛ, весьма aкmуальныл.

Исследуя китайскую ЯЛ в коммуникативном плане, мы можем заключить, что данная ЯЛ весьма успешна в своей коммуникации, прежде всего при решении своих коммуникативных задач: благодаря такому качеству китайской ЯЛ, как проактивность, успешность достигается данной личностью уже на раннем этапе учебного общения, т.е. при овладении ею языковым уровнем A1, т.е. уровнем «выживания». Подчеркнём, в основном современная китайская ЯЛ, изучающая РЯ в условиях России, как показывают наши практические исследования [5; 12]. не интровертивна (о чём ранее утверждалось в работах И.Е. Бобрышевой [2], и не экстравертивна (каковой она является при общении в обиходно-бытовой сфере общения в условиях современных китайских мегаполисов [5], а проактивна: данная личность способна адаптироваться в любой среде, пользуясь как экстравертивныли, так и интровертивныли стратегиями общения (в том числе и учебного общения).

По мнению Л.П. Мухаммад, проактивность - это, прежде всего, способность личности ставить цели, планировать свою деятельность, контролировать и корректировать её в заданных условиях [10; 12]. В связи с этой (приобретённой в процессе этнокультурного «взросления») способностью и китайские экстраверты, и китайские интроверты (если это здоровая, уравновешенная ЯЛ) легко преодолевают трудности учебного общения. Интерпретируя научные данные Л.П. Мухаммад, мы можем утверждать, что структура проактивной китайской ЯЛ оптимальным образом соотносится со структурой учебной деятельности, речевой деятельности: она состоит из стадий целеполагания, ориентировки, исполнения, контроля и самоконтроля. 
Далее рассмотрим личностные свойства китайского студента, непосредственно влияющие на когнитивную сторону учебного общения как деятельности. Ранее в отношении иностранного (в том числе и китайского) студента в качестве таких свойств нами выделялись левополушарность/ правополушарность (см. выше). Так, исследование И.Е. Бобрышевой [2] показывает, что китайские студенты в рассматриваемом аспекте - правополушарны, т.е. им свойственен синтетический тип мышления.

Кроме отмеченных выше характеристик китайской ЯЛ следует также добавить: рачиональность и прагматизм китайской ЯЛ. Однако прагматизм китайской ЯЛ не абсолютен, а относителен. Если образованным китайцам приходится выбирать между прагматически выгодным вариантом и «культурными заповедями», вытекающими из концепции великого Конфуция, то большинство этих людей (в том числе и студентов) выбирает культуру (в языковом сознании китайских людей эта культура - «великая культура»).

В соответствии с учением Конфуция китайцам нужно планировать работу заранее, читая, подождать и посмотреть ещё раз в текст - очень нужно, чтобы четко представить себе, о чём идёт речь. Большинство студентов способны с терпением заниматься грамматикой и упражнениями, в учебном процессе они много думают о точности использования грамматики, благодаря чему ошибок они делают меньше; однако на начальном этапе обучения они медленно выполняют любой вид РД (речевой деятельности), особенно медленно говорят и пишут.

Результаты проведённых нами практических исследований позволили, кроме отмеченных, выделить следующие основные психологические особенности современной ЯЛ китайского студента (лингводидактически значимые особенности):

1. Сегодня китайская молодежь по сравнению с предшествующим поколением более открыта. В современном Китае с детства начинают изучать ИЯ, и родители ... создают детям условия для изучения языков. У китайских детей, особенно в больших городах, есть много шансов общаться с иностранцами. 
2. В настоящее время, особенно в условиях иной (не китайской) культуры, весьма трудно выявить базовый «типаж» китайского студента, поскольку: а) одни китайские студенты любят самостоятельно заниматься: они любят получать информацию на изучаемом языке из книг; б) другие - предпочитают общаться в диалоге; в) часть студентов любит размышлять, видоизменять воспринятую речь, генерировать идеи; г) другая часть - воспринимать и репродуцировать чужие идеи.

3. Китайский «интроверт»/«экстраверт», изучающий РЯ в «чужой» этнокультурной среде (т.е. в условиях России), - понятие относительное. Особенно большая разница между китайскими «интровертами» уровней A1 и A2. «Начинающий» китайский интроверт, не прошедший уровень A1 (с его стратегией «выживания»), или прошедший данный уровень по стандартным методикам (не предусматривающим интерактивный курс адаптации данного студента в новой для него среде) - явление, вызывающее сочувствие и тревогу за его судьбу. Он бессилен и растерян ещё и потому, что его ум, его ЯЛ привыкли к иероглифу, к совершенно иной системе координат, чем это даёт РЯ с его звуко-буквенными соответствиями.

Однако большинство китайских «начинающих» студентов - это студенты, успешно прошедшие в своей стране кунфуцианскую школу проактивности. В учебном общении на ИЯ/РЯ они, в целях «выживания», используют стратегии интровертированной личности, поэтому со стороны кажутся интровертами. Обычный преподаватель (а не преподаватель-психолог) так их и воспринимает как интровертов.

4. Китайским «интровертам» уровня А2, находящимся в «чужой» среде, т.е. в условиях России (их до 30\%) говорить тяжелее, чем слушать; «экстравертам» (их на данном уровне обучения совсем немного: примерно 1-2\%, наоборот, не нравится быть лишёнными внимания, им скучен разговор, если они не могут принимать в нём активного участия. Большинство же китайских студентов, прошедших специальные методики на «уровне выживания» (уровень А1) - это про- 
активные учащиеся, которые в своём поведении сдержанны, слушают преподавателя, изучают обстановку, выполняют задания по рекомендации преподавателя, одним словом, учатся оптимальной коммуникативной деятельности.

5. Большинство китайцев терпеливые и трудолюбивые. Они способны хорошо подготовиться к экзамену. И тем не менее этим студентам на иностранном (русском) языке труднее говорить, чем читать, особенно если они начали изучать русский язык в условиях Китая.

6. Китайцы чувствуют себя некомфортно, если собеседник часто меняет тему разговора. Если же Вы внезапно (случайно) измените тему разговора, нет гарантии, что китайский собеседник поймёт вас.

7. Многие китайские студенты любят исследовать неизвестное, тем не менее, часть китайских людей в большей мере предпочитают работать в пространстве уже утверждённых истин.

По результатам предшествующих теоретических исследований, а также наших собственных наблюдений мы видим, что ЯЛ китайского студента, в целом наделенная теми или иными личностными качествами, предопределяет специфику ее учебной деятельности. Из всего сказанного вытекают следующие лингводидактические выlводы:

1. Для китайских студентов (так же, как и для всех иностранных студентов) весьма полезными являются обучающие модели, которые: а) учитывают особенности китайской ЯЛ и опираются на сильные стороны данной личности; б) развивают компенсаторные стратегии данной личности, т.е. учебные стратегии, не свойственные данной личности, но весьма полезные для её развития и успешного учебного общения/учебной деятельности. В рамках родной этнокультуры китайские студенты, в основном, владеют данными стратегиями. Однако оказываясь в рамках иной культуры и языка, эти студенты испытывают культурный шок и не знают, как применить свои знания и умения при изучении коммуникации на ИЯ/РЯ. 
2. Особенного внимания требуют к себе китайские студенты, начинающие изучать РЯ в условиях России. В этот период в коммуникативном аспекте следует опираться на интровертированные стратегии студентов, применяемые при усвоении небольших микротекстов монологического характера: в этих целях оптимальны микротексты, раскрывающие коммуникативную установку «самопредставление»/«представление кого-либо»: микротекст «О себе», «О друге», «Об известной личности». При работе над образцами-вариантами данных микротекстов поэтапно следует работать над грамматическими формами: формами именительного, винительного, родительного падежей и т. д. Репродуктивное усвоение данных текстов с трансформациями «под себя» следует контролировать индивидуально, на местах. Второй шаг - это публичное самопредставление студента (у доски). Первоначально у доски знакомятся с остальными только самые успешные студенты (преподаватель их выявляет «на местах»).

3. Параллельно, опираясь на умения, выработанные в процессе «монологического общения», развиваются интерактивные качества речи на изучаемом, русском, языке. Первоначально полезны диалогические тексты-образцы, показывающие свойства инициальной и реагирующей реплик. Над грамматическими структурами студенты работают в рамках данных образцов. Постепенно студенты начинают «узнавать» в прагматических и семантических структурах РЯ уже знакомые им структуры китайского языка. Примерно ко второму месяцу обучения по предлагаемой модели студенты осваиваются в коммуникативно-семантическом пространстве РЯ, перестают «бояться» иной культуры и языка, переносят свои проактивные качества в культурно-языковое пространство РЯ. В этот период они всё ещё кажутся «интровертами», но реально уже используют проактивные стратегии, буквально «заставляя» себя быть активными в процессе общения на неродном языке. Имеющиеся в российских вузах языковые программы «выживания» при этом предоставляют студентам нужные языковые формы как оптимальный инструментарий требуемого «выживания». 


\section{Список литературь}

1. Азимов Э.Г. Новый словарь методических терминов и понятий / Э.Г. Азимов, А.Н. Щукин. - М., 2009. - 448 с.

2. Бобрышева И.Е. Культурно-типологические стили учебно-познавательной деятельности иностранных учащихся в методике обучения русскому языку как иностранному. Дисс. ...докт. пед. наук. - М.: 2004. - 390 с.

3. Бобрышева И.Е. Русский язык по-новому // Русский язык за рубежом. M., 2011. - №2. - C. 20-24.

4. Вагнер В.Н. Методика преподавания русского языка англоговорящим и франкоговорящим. - М., 2001. - 384 с.

5. Ван Лися. Грамматика чтения русского языка как иностранного с позиции китайской языковой личности (начальный этап обучения): Магистерская дис. M., 2013. -82 c.

6. Вэнь Яо. Специфика организации языкового материала при обучении китайских студентов-филологов (уровни А1-А2): Магистерская дис. - М., 2014 $75 \mathrm{c}$.

7. Государственный образовательный стандарт по русскому языку как иностранному. Первый сертификационный уровень. Общее владение. М. - СПб.: Златоуст, 2001.

8. Караулов Ю.Н. Русский язык и языковая личность / Ю.Н. Караулов. - 3изд., стереотип. - М.: Едиториал УРСС, 2003. - 264 с.

9. Леонтьев А.А. Язык и речевая деятельность в общей и педагогической психологии. - М. - Воронеж, 2001. - 448 с.

10. Мухаммад Л.П. Языковая личность иностранного студента-нефилолога. - М., 2003. - 240 с.

11. Мухаммад Л.П. Описательный дискурс китайских студентов-филологов в аспекте обучения русскому языку // Гуманитарные, социально-экономические и общественные науки. - Краснодар, 2014. - №7. - С. 139-142. 
12. Мухаммад Л.П. Антропологический принцип при моделировании языковой личности китайского студента в целях обучения / Л.П. Мухаммад, Ван Лися // Российский научный журнал. - Рязань, 2016. - №2 (51). - С. 79-84.

13. Цыренова М.И. Моделирование учебного процесса южнокорейских студентов-филологов: Дис. ... канд. наук. - М., 2013. - 236 с.

14. Щукин А.Н. Методика преподавания русского языка как иностранного: Учеб. пособие. 3-е изд., перераб. и доп. - М.: Флинта; Наука, 2017. - 512 с.

Ван Лися - аспирант ФГБОУ ВО «Государственный институт русского языка им. А.С. Пушкина», Россия, Москва.

Wang Lixia - postgraduate at FSBEI of HE "Pushkin State Russian Language Institute", Russia, Moscow. 